\title{
Configurações
}

Revista Ciências Sociais

\section{O ensino e a divulgação da Sociologia em Portugal: nota introdutória}

ANA MARIA BRANDÃO, BENEDITA PORTUGAL E MELO e JOÃO TEIXEIRA LOPES

\section{(2) OpenEdition}

\section{Journals}

\section{Edição electrónica}

URL: https://journals.openedition.org/configuracoes/14124

DOI: $10.4000 /$ configuracoes. 14124

ISSN: 2182-7419

Editora

Centro de Investigação em Ciências Sociais

Edição impressa

Paginação: 5-10

ISSN: 1646-5075

\section{Refêrencia eletrónica}

ANA MARIA BRANDÃO, BENEDITA PORTUGAL E MELO e JOÃO TEIXEIRA LOPES, «O ensino e a divulgação da Sociologia em Portugal: nota introdutória», Configurações [Online], 28 | 2021, posto online no dia 15 dezembro 2021, consultado o 28 dezembro 2021. URL: http:// 
BRANDÃO, Ana Maria; MELO, Benedita Portugal; LOPES, João Teixeira - 0 ensino e a divulgação da Sociologia em Portugal: nota introdutória. Configurações [em linha]. 28 (2021) p. 5-10.

\title{
O ensino e a divulgação da Sociologia em Portugal: nota introdutória
}

\author{
ANA MARIA BRANDÃ 0 * \\ CICS - Universidade do Minho \\ BENEDITA PORTUGAL E MELO** \\ UIDEF, Instituto de Educação, Universidade de Lisboa \\ JOÃO TEIXEIRA LOPES*** \\ Instituto de Sociologia e Departamento de Sociologia da Faculdade de Letras da Universidade do Porto
}

Longe vão os tempos em que Adérito Sedas Nunes redigiu uma breve reflexão sobre os "Problemas da Sociologia em Portugal". Desde 1963, data em que esta foi publicada na revista Análise Social, o panorama alterou-se significativamente no que respeita aos contornos da oferta formativa neste campo disciplinar. A Sociologia está, hoje, claramente firmada enquanto área de formação especializada do Ensino Superior e enquanto área pericial, mas está também presente nos planos de estudos de outras áreas disciplinares e níveis de ensino, incluindo o básico e o secundário. A reflexão dos próprios sociólogos sobre esse percurso, no caso português, é já assinalável. Menos comum, no entanto, tem sido o seu enfoque nos aspetos pedagógicos. Como se ensina e se promove a Sociologia em Portugal? Em que moldes se dá a conhecer o conhecimento sociológico a públicos não familiarizados com esta ciência? Com que questões pedagógicas se confrontam os seus professores quer ao nível dos ensinos básico e secundário, quer da oferta graduada e pós-graduada, especializada ou não? Quais as suas preocupações e que instrumentos e estratégias pedagógicos mobilizam? Que experiências pedagógicas concretas têm desenvolvido e quais os seus resultados? Como se relacionam essas preocupações, instrumentos, estratégias e experiências com as características diversificadas dos públicos com que trabalham?

* E-mail: anabrandao @ics.uminho.pt | ORCID ID: http://orcid.org/0000-0001-6594-1563

**E-mail: mbmelo@ie.ulisboa.pt | ORCID ID: http://orcid.org/0000-0003-1981-5931

*** E-mail: jlopes@letras.up.pt | ORCID ID: http://orcid.org/0000-0001-6891-7411 
Estas questões constituíram o mote para o lançamento deste número temático da Configurações: Revista de Ciências Sociais. Abrimos este número com um primeiro trabalho, assinado por Ana Romão, que se centra num objeto de estudo ainda muito pouco explorado em Portugal: o do ensino da Sociologia na Academia Militar. A partir de uma retrospetiva histórica e de comparações internacionais, esboçam-se tendências relativamente ao modo como foi sendo implementada e legitimada a sociologia militar e enunciam-se desafios ao lugar desta disciplina no âmbito da formação dos profissionais das forças de segurança e das Forças Armadas.

Segue-se um conjunto de trabalhos que tem como propósito mais específico refletir, a partir de relatos de experiências concretas, sobre o modo como se tem divulgado o conhecimento sociológico junto de públicos não familiarizados com esta ciência.

No texto, "Fazer a ciência chegar mais longe: reflexões sobre o outreach universitário”, Maria Manuel Vieira, Lia Pappámikail e Tatiana Ferreira concentram a sua análise na divulgação de ciência entre públicos não académicos, partindo da análise dos principais modelos e paradigmas de divulgação de ciência, incidindo numa iniciativa particular de "extensão universitária", os "Estágios científicos de Verão" para estudantes do ensino secundário, dinamizada no OPJ/ICS-ULisboa. Esta opção permitiu a deteção de variáveis relevantes que, todavia, escapam a um nível macro: dificuldade de articulação entre os repertórios do campo científico, do meio escolar, dos meios de comunicação e da vida quotidiana, por um lado; crescentes exigências às quais as instituições estão sujeitas, aliada a uma relativa falta de recursos específicos para iniciativas de promoção da cultura científica, por outro. Verificou-se, ainda, em geral, uma atitude de resistência de setores do campo académico que desconfiam da relevância e da centralidade destas iniciativas.

No artigo "Olhar sociológico sobre o mundo: debates nas escolas secundárias. Reflexões e práticas no Norte e Centro do País”, Ângela Alves, Beatriz Lacerda, Cátia Costa, Cristina Parente e Natália Azevedo discutem a relevância científica e pedagógica de experiências de divulgação da disciplina da Sociologia a públicos estudantis das escolas secundárias portuguesas. Estas experiências, concebidas e implementadas por estudantes do Departamento de Sociologia da Faculdade de Letras da Universidade do Porto, com o apoio de docentes daquele curso, a partir do repto lançado pela Associação Portuguesa de Sociologia, em 2017, procuram salientar o olhar sociológico na análise de temas sociais estruturantes e os possíveis perfis profissionais de futuros licenciados em Sociologia, com vista a capacitar os jovens do ensino secundário para uma participação consciente na vida social e política. Mas, para além disso, como justificam as suas autoras, têm constituído uma oportunidade para os estudantes dos $2 .^{\circ} \mathrm{e}$ 3. ${ }^{\circ}$ anos da licenciatura e do $1 .^{\circ}$ ano do mestrado em Sociologia refletirem sobre a sua própria experiência educativa e, a partir dela, construírem conteúdos e 
materiais pedagógicos, equacionando formas de os transmitir num exercício explicativo e informativo de educação de pares. Para além de refletir sobre as vantagens desta educação realizada entre pares, o artigo apresenta uma análise reflexiva sobre o modo como foram concebidas, planeadas e concretizadas, entre 2017 e 2020, as onze sessões de divulgação da sociologia em escolas secundárias do norte e centro de Portugal, acompanhada da descrição dos objetivos, conteúdos, dinâmicas e recursos mobilizados naqueles encontros e de uma avaliação cuidada dos resultados obtidos. Este artigo constitui, assim, um inspirador "guia de ação" para todos os que pretendam desenvolver atividades que tenham como propósito divulgar a sociologia a públicos não familiarizados com esta ciência em contextos escolares.

Um conjunto de textos procura, seguidamente, discutir os desafios e constrangimentos associados ao ensino de determinadas teorias e conceitos sociológicos, analisando em que medida a mobilização de determinados recursos (como filmes, questionários e avaliação das aprendizagens) e de diferentes estratégias pedagógicas (que promovam a interdisciplinaridade, os trabalhos em grupo ou a aprendizagem colaborativa e a aprendizagem baseada em projetos) pode potenciar 'novos modos de ensinar' sociologia e traduzir-se em ganhos acrescidos na motivação dos estudantes para a aprendizagem deste tipo de saber.

Com base num mapeamento do ensino da sociologia no ensino superior português, o artigo "Reflexões sobre o potencial pedagógico do uso de filmes no ensino e na aprendizagem de Sociologia da Educação e das Culturas Juvenis", assinado por Benedita Portugal e Melo, Natália Alves e Mariana Gaio Alves, começa por salientar a singularidade desta disciplina no panorama nacional para, depois, discutir os fatores que têm contribuído para uma alteração dos currículos no ensino superior, entre os quais se destacam a crescente diversidade do público estudantil universitário a que corresponde uma composição sociocultural e económica heterogénea, vários trajetos de vida pessoal e escolar e distintas expectativas para o futuro. Defendendo que esta disciplina constitui um ponto de aplicação para ensinar sociologia, as autoras justificam as competências e objetivos de ensino-aprendizagem desta Unidade Curricular (UC), refletindo também sobre os constrangimentos institucionais que influenciaram as suas opções pedagógicas. Discutem, depois, mais aprofundadamente, o potencial didático dos filmes enquanto recursos passíveis de ser mobilizados no ensino da Sociologia da Educação e das Culturas Juvenis e os resultados que daí têm advindo. As autoras concluem que o ensino de teorias e conceitos sociológicos é facilitado pelo recurso a materiais não académicos, como os filmes, e que estes contribuem para a promoção de uma consciência crítica face a fenómenos sociais em cuja construção os estudantes também participam, com a vantagem de os predispor mais favoravelmente à aprendizagem da sociologia.

Em "Género(s) e sexualidade(s): uma experiência de ensino em contexto académico", Ana Maria Brandão, Sérgio Antônio Silva Rêgo e Joana Teixeira 
Ferraz da Silva refletem sobre o ensino da sociologia do Género e da Sexualidade a partir da experiência acumulada na lecionação de uma UC opcional da licenciatura em Sociologia da Universidade do Minho com essa designação, que é também oferecida a todos os outros cursos desta instituição de ensino superior. Considerando que este é um campo de estudos altamente politizado e propenso a investimentos emocionais e morais diversos, os autores identificam um conjunto de desafios que se colocam ao seu ensino, onde se incluem a necessidade de lidar com as expectativas dos seus públicos de melhorar o autoconhecimento e de obter instrumentos para a praxis, por um lado, e o necessário distanciamento face às circunstâncias pessoais que a abordagem sociológica dos fenómenos sociais exige e as dificuldades pedagógicas resultantes da copresença de estudantes com percursos formativos distintos, por outro. Partindo dos dados de um inquérito por questionário, os autores começam por traçar o perfil dos públicos da UC, incluindo uma análise dos seus valores, atitudes e representações face ao género e à sexualidade, para, depois, discutir a estratégia pedagógica adotada. Recorrendo a registos de avaliação da aprendizagem, defendem as vantagens de estratégias pedagógicas interativas e participativas que, a partir das experiências e inquietações pessoais dos/as estudantes, permitam reduzir o grau de abstração de teorias e conceitos e melhorar a sua capacidade de refletir sobre os fenómenos sociais e enquadrar sociologicamente as suas circunstâncias pessoais. A diversidade interna de uma turma é-nos, assim, apresentada não só como um desafio, mas também como uma oportunidade de aprendizagem académica, pessoal e coletiva.

Maria Manuela Mendes e Teresa V. Sá apresentam-nos, de seguida, uma reflexão assente na sua experiência de lecionação da UC de Sociologia em três ciclos de estudos em Arquitetura e Urbanismo de uma instituição do ensino superior público. Intitulado "O ofício do Professor: experiências pedagógicas no ensino da Sociologia em cursos superiores de Arquitetura e Urbanismo", este artigo procura identificar as dificuldades, tensões e desafios que têm acompanhado a sua prática pedagógica. Traçando historicamente a relação entre Sociologia, Arquitetura e Urbanismo, as autoras sublinham o crescente reconhecimento da necessidade de arquitetos e urbanistas considerarem os fatores sociais na elaboração de projetos. Embora esta tendência se tenha vindo a traduzir numa gradual ampliação dos papéis profissional e social desses profissionais, as autoras não deixam de sublinhar a aparentemente paradoxal perda de espaço das ciências sociais, em geral, e da sociologia, em particular, nos planos de estudo destes cursos, fenómeno a que também aludem outros trabalhos publicados neste número. Partindo de uma reflexão sobre o que entendem dever ser uma prática pedagógica que garanta as condições adequadas de aquisição do saber sociológico em articulação com a área central de formação dos estudantes, mas garantindo, simultaneamente, a "fidelidade aos conteúdos" das UC, as autoras apresentam e discutem duas experiências pedagógicas concretas que 
visam estimular a reflexão dos estudantes acerca dos destinatários dos seus projetos - pessoas e territórios, suas particularidades e dinâmicas próprias -, procurando levá-los a refletir sobre as dimensões humana e política da arquitetura e do urbanismo. O tex to termina com um conjunto de desafios e propostas concretas que visa ampliar e consolidar o diálogo entre a Sociologia, a Arquitetura e o Urbanismo quer ao nível do ensino, quer da investigação e da intervenção.

Também Sandra Gomes discute o ensino de conteúdos da Sociologia a públicos de não sociólogos - neste caso, futuros profissionais na área da gestão. Num artigo intitulado "Fornecer leituras sociológicas da realidade: prática pedagógica da sociologia no ensino de não sociólogos", a autora dá conta da sua experiência de lecionação da UC Comportamento Organizacional baseada na aprendizagem colaborativa. Partindo também de uma discussão acerca do papel da Sociologia e de uma socióloga numa instituição de ensino superior privado onde a disciplina tem vindo a perder espaço, a opção pela aprendizagem colaborativa pretende responder às características e expectativas de públicos que valorizam particularmente a aplicação dos conhecimentos. A autora apresenta-nos, depois, a estratégia pedagógica adotada num módulo sobre Responsabilidade Social das Organizações, assente em trabalhos de grupo sobre casos reais que são, posteriormente, sujeitos a uma avaliação inter e intra-pares, mas também a uma avaliação - e eventual premiação - por parte das organizações analisadas. Uma avaliação cuidada da metodologia de ensino-aprendizagem adotada e dos seus resultados concretos, em termos de aquisição de conhecimentos, revela as suas vantagens pedagógicas, a que corresponde um elevado grau de satisfação dos estudantes quer com esta metodologia de ensino e aprendizagem, quer com a UC na sua globalidade. Ao mesmo tempo, permite detetar lacunas ou aspetos menos conseguidos e, portanto, a melhorar.

Uma outra visão dos trabalhos de grupo como instrumento pedagógico é-nos trazida por Sofia Bento, Rosalina Costa e Emília Araújo no texto intitulado "Trabalhos de grupo no ensino da Sociologia: práticas, discursos e tensões". Centrando-se, desta feita, no ensino da Sociologia a futuros sociólogos, as autoras analisam a relevância dos trabalhos de grupo, identificando alguns dos desafios que esta metodologia de ensino e aprendizagem suscita. O estudo de caso (que resulta da disseminação entre estudantes universitários de um pequeno inquérito por questionário anónimo, intitulado "Dinâmicas de Grupo e Ensino-Aprendizagem da Sociologia") sustenta a relevância da implementação de formas mais ativas e autónomas de trabalho em sala de aula, mobilizadas como instrumento de avaliação regular, permitindo o desenvolvimento de competências relacionais e de soft skills, treinando a construção de argumentos e a construção dialógica de compromissos. As autoras destacam e problematizam as avaliações que os próprios estudantes fazem desta metodologia tanto em termos das vantagens que lhe reconhecem, como das desvantagens e dificuldades com que se confrontam. Mas ilustram, igualmente, aspetos associados à 
sua aplicação que nem sempre são (re)conhecidas pelos próprios docentes e que constituem pistas importantes de reflexão.

Encerra este número o tex to "A promoção centrífuga do ensino da sociologia", da autoria de António Pedro Dores, que discute a forma como a conjuntura histórica atual tem impedindo o aumento do prestígio da sociologia e propõe que sejam repensadas determinadas práticas académicas e científicas para que as ciências sociais - e, concretamente, a sociologia - voltem a adquirir capacidade para antecipar o futuro, contribuindo construtivamente para a sua transformação. O autor começa por traçar o quadro que marca o exercício de uma sociologia "centrípeta" para depois defender a sua transformação em "sociologia centrífuga". No diagnóstico que elabora para justificar a existência da sociologia “centrípeta”, salienta, entre outros fatores, i) a hiperespecialização imposta pelas políticas tecnocientíficas internacionais dominadas pelo utilitarismo, da qual terá resultado uma sociologia estanque às outras ciências sociais, ii) a emergência de "um elitismo profissional competitivo, assediado pelas políticas internacionais de investigação académica e pelas dinâmicas depressivas dos mercados de trabalho"; iii) a valorização dos professores universitários em detrimento dos profissionais que 'aplicam' a sociologia no terreno; iv) a atual fragilidade política da sociologia, em virtude de as disciplinas de ensino da sociologia nos cursos não superiores serem lecionadas prioritariamente por licenciados em outras disciplinas das ciências sociais, ou pelo facto de não haver uma Ordem dos Sociólogos. Defendendo que a sociologia, os sociólogos e as suas instituições, "podem decidir retomar o caminho já percorrido entre a filosofia social e as ciências, aproximando-se, em vez de se incompatibilizarem, com as ciências naturais", António Pedro Dores sugere que a sociologia poderá recuperar o seu prestígio de outrora e o seu importante papel no estudo "da experiência da humanidade", se se transformar em sociologia centrífuga. Trata-se, em suma, de um texto ensaístico que defende uma sociologia aberta "às práticas terapêuticas e atenta à prevenção de consequências das catástrofes, sejam elas naturais ou produzidas e reproduzidas pela ação humana”, capaz de contribuir para que o futuro da Humanidade se transforme em esperança.

\section{Referências bibliográficas}

NUNES, A. Sedas - Problemas da sociologia em Portugal. Análise Social. Lisboa. ISSN: 00032573. 1: 3 (1963), p. 459-464. 